\title{
A service evaluation of the Eczema Education Programme: an analysis of child, parent and service impact outcomes
}

\begin{abstract}
Background: The systematic support of parents of children with eczema is essential to their effective management. The few existing support models have a limited evidence base. This paper reports the outcome-orientated service evaluation of an original, extensive social learning theory based, nurse-led Eczema Education Programme (EEP).
\end{abstract}

Objectives: To evaluate the EEP using specified child and parental outcomes and service impact data.

Methods: From a sample of 257 parent-child dyads attending the EEP, a pretest-posttest design evaluated its child impact using health related quality of life measures (Infant's Dermatitis Quality of Life index, IDQOL, which includes a small dermatitis severity element; Children's Dermatology Life Quality Index, CDLQI), severity measures (Patient Orientated Eczema Measure, POEM), a new parental measure (Parental Self-Efficacy in Eczema Care Index, PASECI) and service impact data based on General Practice (GP) attendance patterns pre-post intervention.

Results: Statistically significant impacts were observed, compared to baseline, on infant quality of life $(p<0.001)$, child quality of life $(p=0.027)$, disease severity $(p<0.001)$ and parental self-efficacy $(p<0.001)$. Improvements in child quality of life, parental efficacy and service impact were also evident from qualitative data. The cumulative total of all GP visits for selected participants post EEP reduced by $62 \%$.

Conclusions: The EEP appears to be an effective model of delivering structured education to parents of children with eczema and one generalizable to other multi-ethnic metropolitan populations. As a non-controlled study, this rigorous service evaluation highlights the model's significance and the case for an evaluative multi-centre randomised controlled trial of this educational intervention to inform a nurse-led programme of care.

\section{Introduction}

Atopic dermatitis is a common chronic inflammatory dermatosis affecting approximately $20 \%$ of children 6-7 years in the UK and US ${ }^{1}$. Epidemiological evidence suggests varying prevalence across countries and ethnic groups within populations ${ }^{2}$. It can significantly impact on the quality of life for both child and family ${ }^{3}$ and frequently leads to healthcare consultations ${ }^{4}$. It is predominantly diagnosed and treated in the community ${ }^{5}$ and managed by parents at home. Access to reliable, disease-specific information to support selfmanagement is infrequent with parents often receive conflicting information from professionals ${ }^{6}$.

Health policy advocates support for self-management of people with long-term skin conditions ${ }^{7}$. There are examples of nurse-led clinics that have delivered education more systematically in primary and secondary care ${ }^{8}$; however, their evaluation is limited. A Cochrane review, now being updated, revealed few robust trials evaluating education interventions for child eczema, with some evidence for two models, multidisciplinary teamled education and nurse-led delivery ${ }^{9}$. There is currently no consensus on the optimal 
models for supporting parents of children with eczema ${ }^{4}$. There is therefore a need for a systematic educational approach to enhance treatment adherence and parental support ${ }^{9}$, ${ }^{10}$. This is the largest scale structured educational programme targeted at parents implemented in the UK and one the largest in Europe.

The focus of this paper is on the programme's evaluation of this nurse-led educational model in relation to the impact on child, parental and service-related outcomes.

\section{Materials and Methods}

The study aim was to build up an accurate picture of the roll out, feasibility, implementation and impact of the EEP intervention as part of a care pathway for children with eczema, with a focus on impact evaluation. The intervention comprised $3 \times 2$-hour structured community-based nurse-led group education sessions developed by a group of practitioners, researchers and educationalists. A 'tool kit' provided structure and timings for each session creating a consistent approach. The initial trainer model was an expertise cascade service delivery model $^{11}$, involving a specialist nurse training and mentoring 23 community based practitioners to deliver the programme locally. Eleven of the nurses (EEP trainers) began delivering programmes. As attrition rates were high due to competing priorities of community staff and acknowledgement of the high level of dermatological expertise required to deliver the sessions confidently this model was discontinued and replaced with specialist nurse delivery, by one of three specialist dermatology nurses. Table 1 summarises the content and theoretical base of the programme the content of which is close to recently published international recommendations ${ }^{12}$.

An evaluative strategy was designed based on a pragmatic methodological approach ${ }^{13}$ to meet the funding body's request for a rigorous service evaluation. Validated tools were used to measure disease related quality of life and disease severity, and a newly developed tool measured parental self-efficacy. Service impact was assessed through review of General Practitioner (GP) records. Qualitative data were collected from parent focus groups. Validity was enhanced through triangulation of quantitative and qualitative data. National Health Service (NHS) research ethics and governance approval was secured.

A purposive sample, based on a knowledge of the population and the purpose of a study, ( $n=257$ parent-child dyads) was obtained by inviting all who attended the programme during the study period ( $n=356$ ) to participate; this includes children with an eczema diagnosis. The study took place in a large inner city UK metropolitan borough with high levels of mobility, ethnic diversity and social deprivation (the 29th most deprived in England), despite having a proportion of more wealthy families ${ }^{14}$. It is acknowledged that this group may not be entirely representative of the common profile of eczema families which is higher middle class ${ }^{15}$ however, it does present it own challenges. Data were collected in the community based EEP delivery sites (eg: Children's and health centres) and by post for follow-up questionnaires. Evaluation data collection focused on the first year of programme delivery, employing quantitative questionnaire and qualitative focus group data. Table 2 provides an overview of data collection and its relationship to the key evaluative quantitative outcome measures. The child outcomes were rated by the parents.

The aim was to obtain a purposive sample of 144 parent-child dyads; that is, $60 \%$ of the 240 available parent-child participants within the first EEP year. This sample was feasible within 
resources and was calculated to have the power to detect a standardised effect size of 0.27 based on a two-sided paired t-test at the $5 \%$ level with $90 \%$ power. There were uncertainties in the likely recruitment from this diverse and transient population. Completeness of data varied by outcome measure (outlined below).

Due to initial low response rates, the questionnaire survey data were collected over an extended 20-month period from parents who attended the EEP between June 2009 and January $2011(n=356)$. A representative sample $(72 \%, n=257)$ responded which constitutes the core evaluative sample. Although participants were sent reminders, participation was lower at follow-up. Figure 1 summarises numbers in the sample at each stage of data collection/analysis.

The focus group sample was recruited using the inclusion criteria of those eligible for EEP referral. Four audio taped focus groups lasting 45-60 minutes were conducted, involving on average 5 parents who had attended the EEP. Twenty mothers and one father participated $(n=21)$. Participants, where possible, were purposively selected for maximum variation such as child age and ethnicity. Questions focused on parental experience of the EEP and its intended outcomes; these were informed by the preliminary analysis of the questionnaire data. Data collection continued until saturation was achieved; that is, no new themes emerged.

For the service impact review a purposive sample of children $(n=87)$ with eczema whose parents had attended the EEP was identified through the database. Selection criteria were applied, namely, one of the child's parents had completed a minimum of two EEP sessions (including one between June 2009 and May 2010) and that their child was registered with a local GP. Data were generated through review of GP records from 23 of 53 participating practices. Resource limitations focused selection pragmatically on the highest referrers. The frequencies of direct consultations with the GP or practice nurse for an eczema-related complaint were recorded for 8 months pre and post the EEP intervention after first attendance.

Predictive Analytics Software (PASW) ${ }^{21}$ was used to analyse the child and parent outcomes. This included the summed total scores for: IDQOL ${ }^{17}$ (<4 year olds), CDLQI ${ }^{16}$ (4-16 year olds), POEM $^{18}$ (0-16 year olds) (tool employed later in the study), dermatitis severity (<4 year olds) and PASECI (parents) ${ }^{19}$. Higher scores indicated worse outcomes for each of the measures, except PASECI where the reverse was true. To achieve a more meaningful scale for the PASECl, the summed scores for this variable were divided by ten. The pre minus post intervention score differences were computed for all the measures except for PASECI, where the reverse was carried out since higher values indicate higher self-efficacy. Cases with complete pre-post data for each measure were selected so the analyses were based on variable sample sizes (Fig. 1). Although the individual items for each measure were summed, they were still treated as ordinal. Following Bland's guidance ${ }^{22}$, Sign tests were used to investigate pre-test post-test differences. However, findings were consistent using paired t-tests, when treating the data as interval, which is how they were considered when determining the effect size that could be detected from the feasible sample size. Service impact data were analysed using Microsoft Excel with the frequency of GP attendance prepost EEP being compared. 
Qualitative data were transcribed verbatim and thematically analysed using content analysis and constant comparison ${ }^{23}$. The aim was to derive 'saturated' interpretive themes (when the researcher is no longer seeing new information) that related to any perceived impact of the EEP on their child's quality of life and parental efficacy with eczema care.

\section{Results}

Child and parent outcome data: details of the demographic profile of those attending the EEP are given in Tables $3 \& 4$. Table 5 reveals highly statistically significant differences in the outcomes on follow up $(p<0.001)$, other than for the CDLQI, which showed significance at the $5 \%$ level for the smaller $(n=21) 4-16$ year age group, with all measures indicating improvement post-intervention. Self-efficacy (PASECI) also showed an improvement in each domain (data not shown).

Service impact data: 59 patient records from 23 different GP practices were reviewed from the 87 identified (68\%). 9 (10\%) patient records were unavailable due to access restrictions and 19 (22\%) were unavailable as the patient had left the GP surgery. 18 of the 59 case records were further excluded because the child was under 8 months old; these could not be standardised for age as follow-up was conducted 8 months pre and post EEP, so the sample was $n=41$. Almost half $(n=20,49.8 \%)$ of the total sample $(n=41)$ were aged $<2$ years, with $29 \%(n=12) 2-6$ years and $22 \%(n=9)$ aged over 6 years. GP visits or practice attendance for an eczema related complaint, ranged from 0-13 visits per patient over the 8-month period pre-EEP and 0-8 visits over the 8-month period post-EEP. The total of all GP visits for selected participants post EEP reduced by $62 \%$ (171 pre EEP versus 65 post EEP). Pre EEP, $27 \%(n=11)$ participants had 6 or more visits to a GP and $73 \%(n=30)$ had 5 or less visits over the 8-month period which includes $2(5 \%)$ patients recording 0 visits. Post EEP, the majority of participants $(98 \%, n=40)$ had 5 or less visits including $13(32 \%)$ patients recording 0 visits and only 1 patient recording 8 visits post EEP.

Qualitative data on parent-child outcomes: Table 6 summarises the themes relevant to disease severity, quality of life and parental self-efficacy.

Several parents said their child's eczema was mild and prior to the EEP they were not sure of the course's relevance until after attendance; for example:-

'I really thought; is this (EEP) relevant to me? He's growing out of it...it's there but it's under control, but then yes it is relevant because I've got the information... and I know what to do now to stop it from getting worse (Parent 5, focus group 1).'

Through the qualitative data parents emphasised their improved confidence from observing practical demonstrations of steroid cream application; for example:

'I think what I was doing was...backing off using them at all, thinking 'oh it will get better, it will get better' and it wasn't and then I was thinking 'oh well I'll just put a tiny, tiny bit on.' Actually, I probably wasn't using enough so you know the whole fingertip thing was really helpful but to have it actually demonstrated.... I feel a hundred times more confident.'

Greater self-efficacy helped parents' communication with GPs, with heightened awareness of how to gain the right treatments for their child. Pre-EEP parents did not always feel they 
were listened to by doctors but after were more confident in discussing their needs and treatment. They felt the GP was more inclined to listen when they realised the parent had relevant knowledge of treatment options:

'One of the advantages was my GP actually listened to me after, When I said to them that I came to this programme the GP actually gave me what I wanted, because he knew what I was talking about.'

The qualitative data also revealed improvements in disease-related infant-child quality of life, with parents believing that the EEP helped them to focus on key factors affecting their child. Sleep loss was cited as a major problem for the parent and child with night-time the worst for scratching. The only solution for some was to sleep with their child. Triggers seemed worse at night when parents felt most alone and isolated:

'it wasn't until I came to the group that it suddenly then sort of twigged in my mind that actually it's because she's getting hotter and she's waking up.... It's not so much 'what is wrong with her, why is she waking up?' I now know what it is so it's like 'OK we can deal with that.'

All focus groups highlighted the significance of the EEP trainer's expertise; for example:

'Expert support, that's the most important one. When I got that, then I felt like I could do it myself and I only had three lessons...'

The focus group data provided qualitative evidence consistent with the questionnaire and service-use data.

\section{Discussion}

The data revealed evidence of the effectiveness of the EEP. The statistically significant quantitative findings for the main outcome measures (primarily for infants as the predominant sample) are supported by the qualitative data; specific areas of congruence are the EEP alleviating quality of life impact and reducing GP attendance.

The quality of life impact of eczema at baseline were moderate for children ${ }^{24}$ and low for infants ${ }^{17}$, although significant improvements were observed in the pre-post change. Sleep loss has also been identified previously ${ }^{24}$. The baseline severity level ${ }^{16}$ and self-efficacy score were also moderate ${ }^{19}$. However, this may reflect that disease severity was not an inclusion criterion to the programme, with GPs identifying parents' requiring support. Parents' global assessment of infant eczema has been found to correlate well with IDQOL ${ }^{26}$. The milder severity of patients seen in community-based studies has been highlighted as a factor making demonstration of effect on eczema severity difficult ${ }^{26}$.

It is difficult to judge from the quantitative data alone what the clinical significance of the outcome effects are, although fairly substantial changes in pre-post differences were observed for the severity (POEM) and self-efficacy measure (PASECI). However, this observation was also evident through the qualitative data.

With the raised self-efficacy scores post-test and supporting qualitative themes on what parents valued about the EEP and their greater understanding of eczema management, it is hypothesised that increased parental self-efficacy in eczema care leads to improved 
eczema-related quality of life and reduced disease severity. The dimensions of the selfefficacy measure embrace both parental understanding to guide effective treatment use and ability to communicate effectively with health professionals. This concurs with another study which revealed parents frustration with trial and error prescribing by GPs and feeling 'fobbed off' ${ }^{27}$. Also this study and ${ }^{27}$ highlighted that dietary matters were a key interest for parents.

Although the evaluation is limited by not being a controlled study with a threat to internal validity, the data triangulation process enables the integration of quantitative and qualitative data observations to have a more rounded indicator of measured and perceived effects of the educational intervention.

The measurement of child disease severity data completed by parents as a proxy measure was more limited in scale due to the late adoption of the POEM measure. The simple severity element of the IDQOL provided limited data alone, but is validated ${ }^{17}$. However, the combined use of these measures appeared to be useful, indicating a likely effect of EEP on alleviating severity. Furthermore, the POEM tool, although 'patient orientated,' has good correlation with the CDLQI measure and global severity assessments ${ }^{18}$.

There were limitations to the service impact data but, although a small sample and uncontrolled data, there is a strong suggestion of a reduction in the frequency of $\mathrm{GP} /$ practice nurse attendance following intervention. Also, very few of the patients for whom records were reviewed had been referred to a specialist or attended the emergency department for eczema treatment. The observation of a link between parental self-efficacy and improved eczema control would explain the reduction in GP appointments post EEP.

The study background reveals there is limited robust evidence on the effectiveness of eczema education models especially those in which interventions can be delivered on a large scale with complex populations. This is the first large scale nurse-led intervention, where as the multidisciplinary-led models, evaluated by Staab et al ${ }^{28,29}$ are more extensive in nature. This study reinforces existing evidence that systematic educational intervention directed at parents (primarily) or children with eczema, can improve disease-related quality of life of the infant/child and alleviate disease severity ${ }^{9}$.

This study adds a new dimension with the measurement of a process-outcome dimension of parental self-efficacy in eczema care. Survey findings are congruent with the in-depth focus group data highlighting the importance of parental ability to manage their child's eczema. Many parents expressed feelings of failure prior to attending EEP. The EEP appeared to enable parents to more effectively manage topical treatments, particularly steroid creams, and communicate with their doctors to secure the right treatments.

In contrast to other nurse-led educational interventions in managing chronic dermatoses the EEP was designed for delivery to a high volume of service users organised into groups. Multidisciplinary group educational intervention was highlighted by Staab et al ${ }^{29}$, but this is the first large scale nurse-led group intervention model reported. Other nurse-led studies ${ }^{30}$, were one to one interventions. One nurse-led group eczema workshop study demonstrated improvement in eczema severity but did not evaluate quality of life ${ }^{32}$. Smaller scale piloted nurse-led group educational interventions with adults with psoriasis have been reported as showing promise ${ }^{33}$. 
This study provides a useful foundation by providing extensive preliminary data examining the feasibility of an original parent group educational intervention programme, led by specialist nurses and delivered in a challenging population by virtue of its deprivation level, population mobility and ethnic variation. The educational approach could be considered what the Medical Research Council refer to as a 'complex intervention' whose development has been consistent with the call to gather preliminary data through recruitment, tool testing, prior exploratory qualitative work and quantitative evaluation ${ }^{34}$.

\section{Conclusions}

This rigorous service evaluation provides statistically significant pre-test post-test and saturated qualitative data which points to the value and effectiveness of the EEP, a major new eczema support programme. The intervention is transferable and the results are generalizable to other ethnically diverse child eczema populations within metropolitan areas in Britain. As such it contributes to the limited evidence based on structured community based nurse-led education targeted at parents of children with eczema. The model's feasibility has been established, although this requires education to be led by specialist dermatology nurses. The study provides a guide to service commissioners on the value of such nurse-led support for children with the common condition of eczema. The hypothesis emerging from the study is that increased parental self-efficacy in eczema care leads to improved eczema-related quality of life and potentially disease severity. This is worthy of robust testing through a multi-centred randomised controlled trials both in the UK and overseas and involving the full range of socio-economic groups.

\section{Acknowledgements}

The authors would like to acknowledge the parents and children who participated, staff from the local Primary Care Trust, the Advisory group, Professor Peter Thomas (statistician) of Bournemouth University and our funding body the Guy's and St. Thomas' Charity London. Dr Fiona Cowdell (University of Hull) for her critical review and editorial suggestions. 


\section{References}

1. The International Study of Asthma and Allergies in Childhood (ISAAC) Steering Committee. Worldwide variation in the prevalence of symptoms of asthma, allergic rhinoconjunctivitis, and atopic eczema: ISAAC. Lancet 1998;351:1225-1232

2. Flohr C. Recent perspectives on the global epidemiology of childhood eczema. Allergol Immunopathol (Madr) 2011; 39: 174-182

3. Alanne $S$, Nermes M, Söderlund R, Laitinen, K. Quality of life in infants with atopic dermatitis and healthy infants: a follow-up from birth to 24 months. Acta Paediatr 2011; 100: e65-e70.

4. Simpson CR, Newton J, Hippisley-Cox J, Sheikh A. Trends in the epidemiology and prescribing of medication for eczema in England. Journal of the Royal Society Medicine 2009; 102: 108-117.

5. Schofield J, Grindlay D, Williams H. Skin Conditions in the UK: a Health Care Needs Assessment. Centre of Evidence-Based Dermatology, University of Nottingham 2009; 1-158.

6. Surridge $\mathrm{H}$. Exploring parental needs and knowledge when caring for a child with eczema: a PhD research study Exchange (National Eczema Society, UK) 2005; 119:32-33.

7. Department of Health (DH) Supporting people with long term conditions to self-care: a guide to developing local strategies and good practice. 2005, London. DH, Crown.

8. Nicol NH, Ersser SJ. The role of the nurse educator in atopic dermatitis. Immunol Allergy Clin North Am 2010; 30: 369-385.

9. Ersser SJ, Latter S, Sibley A et al. Psychological and Educational Interventions for Atopic Eczema in Children. Cochrane Database of Systematic Reviews 3:CD004054. 2007

10. Cork MJ, Britton J, Butler L et al. Comparison of parental knowledge, therapy utilisation and severity of atopic eczemas before and after explanation and demonstration of topical therapies by a specialist dermatology nurse. Br J Dermatol. 2003; 149: 582-589.

11. Ersser $S$, Kaur V, Kelly $P$ et al. The contribution of the nursing service worldwide and its capacity to benefit within the dermatology field. Int J Dermatol 2011; 50: 582589. 
12. Barbarot S, Bernier C, Deleuran M et al Therapeutic Patient Education in Children with Atopic Dermatitis: Position Paper on Objectives and Recommendations. Pediatric Dermatology 2013; 30: 199-206

13. Pawson R, Tilley N. Realistic Evaluation. London. Sage, 1997.

14. NHS Lambeth. Lambeth Health Profile and Outcomes Review. Lambeth Joint Strategic Needs Assessment. London, NHS Lambeth 2012.

15. Williams H, Strachan D, Hay R. Childhood eczema: disease of the advantaged? BMJ. 1994; 308: 1132-1135

16. Lewis-Jones MS, Finlay AY. The Children's Dermatology Life Quality Index (CDLQI): initial validation and practical use. Br J Dermatol. 1995; 132: 942-949.

17. Lewis-Jones MS, Finlay AY, Dykes PJ. The Infants' Dermatitis Quality of Life Index. $\mathrm{Br}$ J Dermatol. 2001; 144: 104-10.

18. Charman RC, Venn AJ, Williams HC. The Patient-Orientated Eczema Measure. Arch Dermatol. 2004; 140: 1513-9.

19. Ersser SJ, Farasat $\mathrm{H}$, Jackson $\mathrm{K}$ et al. Parental Self-Efficacy with Eczema Care Index. (Unpublished questionnaire: version 7), University of Hull: UK, 2012.

20. Bandura A. Self-efficacy: the exercise of control. New York, Freeman 1997.

21. PASW Statistics software v.18 (formerly SPSS: An IBM Company).

22. Bland, M. An Introduction to Medical Statistics. (Third Edition) Oxford: Oxford University Press, 2009.

23. Denzin NK, Lincoln YS. The Sage Handbook of Qualitative Research. London: Sage, 2005.

24. Waters A, Sandhu D, Beattie P et al. Severity stratification of Children's Dermatology Life Quality Index (CDLQI) scores. Br J Dermatol. 2010; 163 (Suppl 1): 121.

25. Elliott BE, Luker $\mathrm{K}$. The experiences of mothers caring for a child with severe atopic eczema. J Clin Nur. 1997; 6:241-7 
26. Beattie PE, Lewis-Jones MS. An audit of the impact of a consultation with paediatric dermatology team on quality of life in infants with atopic eczema and their families: further validation of the Infant's Quality of Life Index and Dermatitis Impact score $\mathrm{Br}$ J Dermatol 2006; 155:1249-1255

27. Santer $M$, Burgess $H$, Yardley $L$ et al. Experiences of carers managing childhood eczema and their views on its treatment: qualitative study Br J Gen Pract 2012; 62: e261-7.

28. Staab D. Von Rueden $U$, Kehrt R et al. Evaluation of a parental training program for the management of childhood atopic dermatitis Pediatr Allergy Immunol. 2002; 13: 84-90.

29. Staab D, Diepgen TL, Fartasch M et al. Age related, structured educational programmes for the management of atopic dermatitis in children and adolescents: multicentre, randomized controlled trial. BMJ. 2006; 332: 933-6.

30. Chinn DJ, Poyner T, Sibley G. Randomized controlled trial of a single dermatology nurse consultation in primary care on the quality of life of children with atopic eczema. Br J Dermatol. 2002; 146: 432-9.

31. Niebel G, Kallweit C, Lange I, Folster-Holst R. Direct versus video-based parental education in the treatment of atopic eczema in children. A controlled pilot study. [Translated] Hautarzt. 2000; 51: 401-11.

32. Moore E, Williams A, Manias E et al Eczema workshops reduce severity of childhood atopic eczema. Australas J Dermatol. 2009; 50; 100-106.

33. Ersser S J, Cowdell F, Nicholls PG. et al Development and Feasibility Testing of an Education Intervention to Improve Self-Management Practice in Patients with MildModerate Psoriasis. J Eur Acad Dermatol Venereol. 2012; 26: 738-745.

34. Medical Research Council (MRC). Developing and evaluating complex interventions: new guidance. London: UK, MRC, 2008. 
EEP BJD RESUB April 2013(2)

Table 1: Eczema Education Programme curriculum topics, rationale for inclusion, evidence- theory base and teaching methods

\begin{tabular}{|c|c|c|}
\hline Subject and rationale & Evidence / theory base & Teaching method \\
\hline $\begin{array}{l}\text { WHAT IS ECZEMA? } \\
\text { Knowledge to sUpport } \\
\text { learning about management } \\
\text { strategies and establish } \\
\text { realistic treatment } \\
\text { expectations }\end{array}$ & NICE guidance & Trainer led discussion \\
\hline $\begin{array}{l}\text { TRIGGER FACTORS } \\
\text { To empower parents to take } \\
\text { positive action in avoiding } \\
\text { triggers where possible }\end{array}$ & NICE guidance & Trainer led discussion \\
\hline $\begin{array}{l}\text { ECZEMA TREATMENT } \\
\text { The key to managing eczema } \\
\text { successfully is the use of } \\
\text { topical treatments }\end{array}$ & $\begin{array}{l}\text { NICE guidance } \\
\text { Self-efficacy theory }\end{array}$ & $\begin{array}{l}\text { Practical demonstrations on } \\
\text { application of topical } \\
\text { treatments. Variety of } \\
\text { emollients to see, touch and } \\
\text { feel }\end{array}$ \\
\hline $\begin{array}{l}\text { TREATMENT PLAN } \\
\text { To support modelling of } \\
\text { positive new behaviours } \\
\text { through development of } \\
\text { treatment plan }\end{array}$ & $\begin{array}{l}\text { Interactive learning } \\
\text { Self-efficacy theory }\end{array}$ & $\begin{array}{l}\text { Completion of individual } \\
\text { treatment plan with support } \\
\text { from trainer }\end{array}$ \\
\hline $\begin{array}{l}\text { FURTHER TREATMENTS } \\
\text { To provide information and } \\
\text { reassurance to parents with } \\
\text { children with more severe or } \\
\text { recalcitrant disease of other } \\
\text { possible therapies. } \\
\text { To understand when to seek }\end{array}$ & Self-efficacy theory & $\begin{array}{l}\text { Trainer led discussion } \\
\text { View, touch, feel garments } \\
\text { and bandages }\end{array}$ \\
\hline
\end{tabular}


EEP BJD RESUB April 2013(2)

\begin{tabular}{|l|l|l|}
\hline advice of specialist. & \\
\hline COPING & Self-efficacy theory & $\begin{array}{l}\text { Trainer led discussion. Group } \\
\text { work and problem solving on } \\
\text { themes identified as difficult } \\
\text { caring for a child with } \\
\text { eczema can be challenging. } \\
\text { Focus is on practical } \\
\text { strategies to find on-going } \\
\text { support }\end{array}$
\end{tabular}


Table 2: An overview of measurement tools used for the outcome measures for children 016 years old with eczema undertaking the Eczema Education Programme, Lambeth 200911

\begin{tabular}{|c|c|}
\hline Key outcomes & Quantitative measurement tools \\
\hline $\begin{array}{l}\text { Child /Infant } \\
\text { disease-related } \\
\text { quality of life }\end{array}$ & $\begin{array}{l}\text { Children's Dermatology Life Quality Index, CDLQI }{ }^{16} \text { : for children aged } 4- \\
16 \text { years (0-30 score) (13) (or) Infant's Dermatitis Quality of Life Index, } \\
\text { IDQOL }^{17} \text { : for infants i.e. child < } 4 \text { years ( } 0-30 \text { score). }\end{array}$ \\
\hline $\begin{array}{l}\text { Disease } \\
\text { (eczema) } \\
\text { severity }\end{array}$ & $\begin{array}{l}\text { 1) Patient Orientated Eczema Measure, POEM }{ }^{18} \text { : parent rating of their } \\
\text { child's eczema severity data (proxy measure). A 7-item } 0-28 \text { score } \\
\text { capturing the frequency of eczema symptoms deemed valid and } \\
\text { reliable. Steering Group recommended using POEM from October } \\
\text { 2010. The sole prior measure of severity in the IDQOL tool is valid }{ }^{16} \text { but } \\
\text { limited in scope. 2) Dermatitis severity scale is also included as a simple } \\
\text { measure within IDQOL. }\end{array}$ \\
\hline $\begin{array}{l}\text { Parental self- } \\
\text { efficacy in } \\
\text { eczema care }\end{array}$ & $\begin{array}{l}\text { Parental Self-efficacy in Eczema Care Index, PASECI: a } 40 \text {-item } \\
\text { questionnaire }{ }^{19} \text { is an intermediate outcome- measuring the parents' } \\
\text { belief in their ability to manage their child's eczema. Only the } 37 \text { items } \\
\text { that related to infants were used. Perceived self-efficacy is an } \\
\text { individual's beliefs in their ability to achieve specific attainments }{ }^{20} \text {. Low } \\
\text { self-efficacy will negatively impact on the parent's management of } \\
\text { eczema and their motivation to follow treatment plans. For each item, } \\
\text { parents rated their self-efficacy on a scale of } 0-10 \text {. Domains measured: } \\
\text { 1) managing medication; } 2 \text { ) managing eczema and symptoms; } 3 \text { ) } \\
\text { communicating with healthcare professionals; } 4 \text { ) managing personal } \\
\text { challenges caring for a child with eczema. This measure underwent } \\
\text { various stages of development; prototypes were rigorously tested for } \\
\text { face/content validity. Its development and reliability analysis will be } \\
\text { reported elsewhere. }\end{array}$ \\
\hline
\end{tabular}


EEP BJD RESUB April 2013(2)

Table 3. Age breakdown of referrals to the Eczema Education Programme, Lambeth 20092011

\begin{tabular}{|l|l|}
\hline Age & Percentage of children \\
\hline$<1$ year & $11 \%$ \\
\hline $1-2$ years & $25 \%$ \\
\hline $2-5$ years & $34 \%$ \\
\hline $5-9$ years & $18 \%$ \\
\hline $10-14$ years & $9 \%$ \\
\hline $15-16$ years & $2 \%$ \\
\hline
\end{tabular}


EEP BJD RESUB April 2013(2)

Table 4. The ethnicity profile of Eczema Education programme, Lambeth 2009-11

\begin{tabular}{|l|l|}
\hline Ethnicity & Percentage of children \\
\hline Asian Chinese & $1 \%$ \\
\hline Asian or Asian British & $3 \%$ \\
\hline Other & $3 \%$ \\
\hline Mixed & $5 \%$ \\
\hline Black African or Caribbean & $23 \%$ \\
\hline White British (incl Irish and other) & $27 \%$ \\
\hline Not stated & $38 \%$ \\
\hline
\end{tabular}


Table 5: Median and inter-quartile range (IQR) for Infant Dermatitis Quality of Life (IDQOL) index, Children's Dermatology Life Quality Index (CDLQI), disease severity (Patient Orientated Eczema Measure (POEM), and dermatitis severity- IDQOL element), and Parental Self-Efficacy with Eczema Care Index (PASECI) for children aged 0-16 years pre and post the Eczema Education Programme, Lambeth 2009-2011

\begin{tabular}{|c|c|c|c|c|}
\hline Outcome & $\begin{array}{l}\text { Pre-intervention } \\
\text { median (IQR) }\end{array}$ & $\begin{array}{l}\text { Post- } \\
\text { intervention } \\
\text { median (IQR) }\end{array}$ & $\begin{array}{c}\text { Median (IQR) } \\
\text { of pre/post } \\
\text { difference }\end{array}$ & $\begin{array}{c}\mathrm{p}- \\
\text { value }\end{array}$ \\
\hline IDQOL for $<4$ year olds & 7.0 & 3.0 & 2.0 & $<0.001$ \\
\hline$(n=116)$ & $(3.0-11.0)$ & $(1.0-6.0)$ & $(-1.0-6.0)$ & \\
\hline CDLQI for 4-16 year olds & 9.0 & 5.0 & 3.0 & 0.027 \\
\hline$(n=21)$ & $(6.5-15.5)$ & $(2.5-11.5)$ & $(0.0-8.0)$ & \\
\hline POEM & 15.0 & 5.0 & 7.0 & $<0.001$ \\
\hline$(n=45)$ & $(9.0-20.0)$ & $(2.0-10.0)$ & $(0.0-13.0)$ & \\
\hline Dermatitis severity (IDQOL) & 2.0 & 1.0 & 0.0 & $<0.001$ \\
\hline$(n=113)$ & $(1.0-3.0)$ & $(1.0-2.0)$ & $(0.0-1.0)$ & \\
\hline PASECI & 24.5 & 31.4 & 5.6 & $<0.001$ \\
\hline$(n=100)$ & $(17.8-30.4)$ & $(28.1-34.4)$ & $(1.9-11.1)$ & \\
\hline
\end{tabular}

Post-intervention scores were subtracted from the pre-intervention scores except for PASECI where pre-scores were subtracted from the post-intervention score because a higher score indicated higher self-efficacy; PASECI results divided by 10 to put on a more meaningful 0-37 scale. Medians, inter-quartile ranges (IQRs) and p-values based on the Sign test are presented since the data were treated as ordinal but findings were consistent when using paired t-tests. 
Table 6: Summary of qualitative data themes and categories related to parent-child outcomes arising from the parent focus groups to evaluate the Eczema Education

Programme in Lambeth 2009-10

\begin{tabular}{|l|l|}
\hline Themes & Categories \\
\hline $\begin{array}{l}\text { 1.Improvements in the experience of living } \\
\text { with eczema }\end{array}$ & $\begin{array}{l}\text { Perceived improvement in child quality of life and } \\
\text { parental quality of life } \\
\text { Feeling less isolated } \\
\text { Sleep problems persist but parent feels more in } \\
\text { control. }\end{array}$ \\
\hline $\begin{array}{l}\text { w.Increased confidence in communication } \\
\text { with health professionals }\end{array}$ & $\begin{array}{l}\text { Feeling more confident talking to doctors } \\
\text { Realising what the gap is in General Practitioners' } \\
\text { (GP) responses } \\
\text { Recognising conflicting and/or inconsistent advice } \\
\text { Getting the right treatment }\end{array}$ \\
\hline services & $\begin{array}{l}\text { The parents felt that they were making fewer } \\
\text { visits to the GP after attending EEP and that they } \\
\text { were able to gain the information or treatment } \\
\text { that they needed }\end{array}$ \\
\hline
\end{tabular}

